\title{
Motoneuron Apoptosis Is Blocked by CEP-1347 (KT 7515), a Novel Inhibitor of the JNK Signaling Pathway
}

\author{
Anna C. Maroney, ${ }^{1}$ Marcie A. Glicksman, ${ }^{1}$ Alie N. Basma, ${ }^{1}$ Kevin M. Walton, ${ }^{1}$ Ernest Knight $\mathrm{Jr},{ }^{1}$ \\ Carol A. Murphy, ${ }^{1}$ Becky A. Bartlett, ${ }^{1}$ James P. Finn, ${ }^{1}$ Thelma Angeles, ${ }^{1}$ Yuzuru Matsuda, ${ }^{2}$ Nicola T. Neff, ${ }^{1}$ and \\ Craig A. Dionne ${ }^{1}$

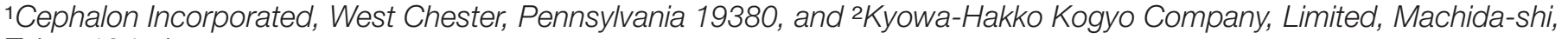 \\ Tokyo 194, Japan
}

Neurons undergoing apoptosis can be rescued by trophic factors that simultaneously increase the activity of extracellular signal-regulated kinase (ERK) and decrease c-Jun N-terminal kinase (JNK) and p38. We identified a molecule, CEP-1347 (KT7515), that rescues motoneurons undergoing apoptosis and investigated its effect on ERK1 and JNK1 activity. Cultured rat embryonic motoneurons, in the absence of trophic factor, began to die 24-48 hr after plating. During the first $24 \mathrm{hr}$ ERK1 activity was unchanged, whereas JNK1 activity increased fourfold. CEP-1347 completely rescued motoneurons for at least 72 hr with an $\mathrm{EC}_{50}$ of $20 \pm 2$ nM. CEP-1347 did not alter ERK1 activity but rapidly inhibited JNK1 activation. The $\mathrm{IC}_{50}$ of CEP1347 for JNK1 activation was the same as the $\mathrm{EC}_{50}$ for motoneuron survival. Inhibition of JNK1 activation by CEP-1347 was not selective to motoneurons. CEP-1347 also inhibited

During development, populations of neuronal embryonic cells in vivo undergo a predetermined process of programmed cell death (PCD) (for review, see Oppenheim, 1991). In particular, between embryonic days 14.5 and $18 \sim 50 \%$ of rat spinal cord motoneurons undergo a form of PCD morphologically identified as apoptosis. Cultures of motoneurons isolated from E14.5 rat spinal cord also apoptose in vitro (Comella et al., 1994; Milligan et al., 1994). Cell death in this relatively pure population of neurons can be partially prevented by the addition of growth factors such as brain-derived neurotrophic factor and insulin-like growth factor-1 (Henderson et al., 1993; Hughes et al., 1993). Because the environmental cues leading to in vivo apoptosis of motoneurons are not well understood, cultures enriched for motoneurons provide a useful, relatively homogeneous model for identifying neuronal survival agents and examining the biochemical events that govern survival.

Growth factors may mediate neuronal survival by regulating signaling cascades downstream of the small GTP binding proteins ras, rac, and cdc42 (for review, see Denhardt, 1996). Activation of the small GTP binding proteins leads to modulation of serine/ threonine kinases in the mitogen-activated protein kinase

\footnotetext{
Received June 11, 1997; revised Oct. 6, 1997; accepted Oct. 15, 1997.

We thank J. Silvio Gutkind for providing the MEKK and JNK vectors, Anne Camoratto for helpful review of this manuscript, and Judy Richardson for manuscript preparation.

Correspondence should be addressed to Dr. Anna Coco Maroney, Cephalon Incorporated, 145 Brandywine Parkway, West Chester, PA 19380.

Dr. Glicksman's present address: DuPont Merck, Experimental Station, Route 141 and Henry Clay Road, Wilmington, DE 19880.

Dr. Murphy's present address: Institute of Toxicology, Schorenstrasse 16, Schwerzenbach CH-8603, Switzerland.

Copyright (C) 1997 Society for Neuroscience $0270-6474 / 97 / 180104-08 \$ 05.00 / 0$
}

JNK1 activity in Cos7 cells under conditions of ultraviolet irradiation, osmotic shock, and inhibition of glycosylation. Inhibition by CEP-1347 of the JNK1 signaling pathway appeared to be selective, because CEP-1347 did not inhibit p38-regulated mitogen-activated protein kinase-activated protein kinase-2 (MAPKAP2) activity in Cos7 cells subjected to osmotic shock. The direct molecular target of CEP-1347 was not JNK1, because CEP-1347 did not inhibit JNK1 activity in Cos7 cells cotransfected with MEKK1 and JNK1 cDNA constructs. This is the first demonstration of a small organic molecule that promotes motoneuron survival and that simultaneously inhibits the JNK1 signaling cascade.

Key words: motoneurons; indolocarbazole; CEP-1347; survival; apoptosis; c-Jun N-terminal kinase; mitogen-activated protein kinase; p38
(MAPK) family. Specifically, activation of ras leads to phosphorylation and activation of extracellular receptor-activated kinase (ERK), which has been linked biologically to growth and differentiation processes, whereas stimulation of rac/cdc42 leads to an increase in the activity of $\mathrm{JNK}$ and p38, a response that is associated with stress and apoptosis. In neuronally differentiated PC12 cells, withdrawal of NGF causes apoptosis that is preceded by a decrease in ERK activity and an increase in $\mathrm{JNK} / \mathrm{p} 38$ activity (Xia et al., 1995). These results suggest that ERK and $\mathrm{JNK} / \mathrm{p} 38$ are tightly coupled in an opposing relationship to each other. However, more recent studies indicate that inhibition of ERK activation failed to block NGF-dependent survival of superior cervical ganglion (SCG) neurons (Creedon et al., 1996; Virdee et al., 1996). Furthermore, insulin promotes survival of fetal chick forebrain neurons concomitant with inhibition of p38 in the absence of an effect on ERK and JNK activity (Heidenreich and Kummer, 1996). Clearly, the activity of several MAPK members is altered during apoptosis, but at present it is uncertain which, if any, of these activities is necessary and/or sufficient for neuronal apoptosis.

In an effort to identify small molecules that promote neuronal survival, we selected CEP-1347, also known as KT7515, for its ability to induce choline acetyl transferase (ChAT) activity in cultures prepared from embryonic spinal cord and basal forebrain tissue (Kaneko et al., 1997). CEP-1347 is a semisynthetic derivative of the fermentation product K-252a, an indolocarbazole that promotes neuronal survival in chick dorsal root ganglion cultures (Borasio, 1990) and ChAT activity in cultures of rat embryonic spinal cord (Glicksman et al., 1993), basal forebrain, and striatal 
neurons (Glicksman et al., 1995); it also protects hippocampal, septal, and cortical cultures against glucose deprivation-induced death (Cheng et al., 1994). CEP-1347 effectively protects motoneurons in several in vivo models of PCD such as the postnatal rat motoneurons of the spinal nucleus of the bulbocavernosus, adult rat hypoglossal axotomy, and chick lumbar motoneurons in ovo (M. Glicksman, unpublished observation). To elucidate the mechanism by which CEP-1347 promotes survival of motoneurons in vivo, we examined the survival activity and determined the effect of CEP-1347 on members of the MAPK family in cultures enriched for embryonic motoneurons.

\section{MATERIALS AND METHODS}

Materials. CEP-1347, also known as KT7515, is a semisynthetic derivative of K-252a provided by Kyowa-Hakko Kogyo (Tokyo, Japan) (Kaneko et al., 1997). CEP-1347 was dissolved in cell culture grade dimethylsulfoxide (DMSO) and stored in the dark at $4^{\circ} \mathrm{C}$. All dilutions of CEP-1347 were made in DMEM containing $1 \%$ bovine serum albumin. c-Jun N-terminal kinase 1 (JNK1) antibody (catalog \#sc-474-G) was purchased from Santa Cruz Biotechnology (Santa Cruz, CA). ERK1 antibody (catalog \#06-182), mitogen-activated protein kinase-activated protein kinase 2 (MAPKAP2) antibody (catalog \#06-534), and MAPKAP2 peptide substrate (catalog \#12-240) were purchased from Upstate Biotechnology (Lake Placid, NY). HA antibody was purchased from Babco (Richmond, CA). AP-1 (c-jun) substrate was purchased from Promega (Madison, WI). Myelin basic protein substrate, Hoechst dye, and tunicamycin were purchased from Sigma (St. Louis, MO). SB203580 was custom-synthesized by RIT International Technology (Snellville, GA). $\left[\gamma^{-32} \mathrm{P}\right]$ ATP $(6000 \mathrm{Ci} / \mathrm{mmol})$ was purchased from Amersham (Arlington Heights, IL).

Rat spinal cord cultures enriched for motoneurons. Spinal cords were dissected from Sprague Dawley rat fetuses (Charles River Laboratories, Wilmington, MA) of embryonic age (E) 14.5-15. Cells from only the ventral portion of the spinal cord were dissociated and further enriched for motoneurons by centrif ugation on a $6.5 \%$ step metrizamide gradient, as described previously (Henderson et al., 1993), and were analyzed for purity by staining with low-affinity neurotrophin receptor antibody (IgG192, Boehringer Mannheim, Indianapolis, IN) (data not shown). Cells were seeded onto 96-well plates previously coated with poly-L-ornithine and laminin $\left(5 \mu \mathrm{g} / \mathrm{ml}\right.$ each) at a density of $6 \times 10^{4}$ cells $/ \mathrm{cm}^{2}$ in chemically defined serum-free N2 medium (Bottenstein and Sato, 1979). To separate attachment from survival effects, we added CEP-1347 to the cultures after an initial attachment period of 1-3 hr. Neuronal survival was assessed after $4 \mathrm{~d}$ by using calcein AM (Molecular Probes, Eugene, OR) in a fluorimetric viability assay (Bozyczko-Coyne et al., 1993). Microscopic counts of neurons correlated directly with relative fluorescence values. In brief, culture medium was diluted serially in DPBS (Dulbecco's PBS), and a final concentration of $6 \mu \mathrm{M}$ calcein AM stock was added to each 96 -well plate. The plates were incubated for $30 \mathrm{~min}$ at $37^{\circ} \mathrm{C}$, followed by serial dilution washes in DPBS. The fluorescent signal was read with a plate-reading fluorimeter from Millipore (Cytofluor 2350; Bedford, MA) at an excitation equal to $485 \mathrm{~nm}$ and an emission equal to $538 \mathrm{~nm}$. For each plate, mean background derived from wells receiving calcein AM, but containing no cells, was subtracted from all values. Linearity of the fluorescence signal was verified for the concentration and incubation time for the range of cell densities in these experiments.

For assessing apoptotic nuclei, we plated enriched motoneuron cultures onto eight-chamber slides (Lab-Tek, Nunc, Naperville, IL); they were fixed with $4 \%$ paraformaldehyde for $20 \mathrm{~min}$, rinsed with DPBS, and then stained with $1 \mu \mathrm{g} / \mathrm{ml}$ Hoechst dye for $15 \mathrm{~min}$. After staining, cells were rinsed again and coverslipped, using the aqueous mountant Fluoromount (Vector Laboratories, Burlingame, CA), and then they were examined and photographed with a Nikon Diaphot microscope (Garden City, NY).

Cos 7 cell culture. Green monkey kidney Cos7 cells were obtained from American Type Culture Collection (CRL 1651; Rockville, MD) and maintained in DMEM containing $10 \%$ bovine serum, $2 \mathrm{~mm}$ glutamine, 1 $\mathrm{mm}$ pyruvate, and $50 \mathrm{U} / \mathrm{ml}$ penicillin/streptomycin at $37^{\circ} \mathrm{C}$ in $10 \% \mathrm{CO}_{2} /$ $90 \%$ air atmosphere. Cos 7 cells were detached for passaging by adding $0.25 \%$ trypsin.

In vitro kinase activity. The inhibitory activities of various concentrations of K-252a and CEP-1347 were measured in kinase assays. Partially purified protein kinase $\mathrm{C}(\mathrm{PKC})$ was prepared from rat brain, and the holoenzyme of cyclic adenosine monophosphate-dependent protein kinase type I (PKA) was partially purified from rabbit skeletal muscle as described (Kase et al., 1987). Phosphoinositol serine- and $\mathrm{Ca}^{2+}$. dependent PKC activities were assayed under the conditions described, using $200 \mu \mathrm{g} / \mathrm{ml}$ histone $\mathrm{H}-\mathrm{I}$ and $5 \mu \mathrm{M}\left[\gamma^{-32} \mathrm{P}\right] \mathrm{ATP}$ (Kase et al., 1987). The activity of PKA was assayed in the presence of $100 \mu \mathrm{g} / \mathrm{ml}$ histone II-AS and $10 \mu \mathrm{M}\left[\gamma_{-}{ }^{32} \mathrm{P}\right] \mathrm{ATP}$ by the methods in Kase et al. (1987). Myosin light chain kinase (MLCK) was purified from chicken gizzard and assayed as previously described by HPLC analysis (Nakanishi et al., 1991). Phosphatidylinositol-3 kinase (PI3K) was partially purified from calf thymus and assayed as described in Yano et al. (1993). The tyrosine kinase activity of the cytoplasmic domain of human recombinant trkA was assessed in an ELISA assay (Angeles et al., 1996). The $\mathrm{IC}_{50}$ values reported in Table 1 were calculated from plots of the percentage of inhibition versus $\log _{10}$ concentration of the compound.

Immunoprecipitation and kinase assay from whole cells. Purified motoneurons were plated at a density of $6 \times 10^{4}$ cells $/ \mathrm{cm}^{2}$ in $16-\mathrm{mm}$ diameter wells. Cells were allowed to attach for $2 \mathrm{hr}$ before treatment. Cells were treated with either $0.0125 \%$ DMSO or $500 \mathrm{nM}$ CEP-1347 for the indicated time points in defined N2 medium. Then cells were rinsed with ice-cold PBS, followed by lysis in $0.4 \mathrm{ml}$ of Triton buffer (1\% Triton $\mathrm{X}-100,50 \mathrm{~mm}$ sodium chloride, $10 \mathrm{~mm}$ Tris, $\mathrm{pH}$ 7.6, 0.1\% bovine serum albumin, $30 \mu \mathrm{M}$ sodium pyrophosphate, $50 \mathrm{~mm}$ sodium fluoride, $20 \mu \mathrm{g} / \mathrm{ml}$ aprotinin, $1 \mathrm{~mm}$ phenylmethylsulfonylfluoride, $5 \mu \mathrm{g} / \mathrm{ml}$ leupeptin, and 1 $\mathrm{mM}$ sodium vanadate). Immunoprecipitation and kinase assay were performed as previously described (Maroney et al., 1995). Lysate from motoneuron cultures was normalized to cell number, and lysate from Cos7 cells was normalized to protein concentration. For JNK1 and ERK1 immunoprecipitations, antibodies were used as recommended by the providers. Immunoprecipitates were rinsed three times with Triton buffer, followed by a final wash in kinase buffer (20 mM HEPES, pH 7.4, $20 \mathrm{mM} \mathrm{MgCl}_{2}, 2 \mathrm{~mm}$ dithiothreitol, and $0.1 \mathrm{~mm}$ sodium vanadate). Reactions were incubated in kinase buffer containing $1 \mu \mathrm{M}$ ATP and 5 $\mu \mathrm{Ci}\left[\gamma^{-32} \mathrm{P}\right] \mathrm{ATP}$ and substrate $(20 \mu \mathrm{g} / \mathrm{sample}$ of myelin basic protein for ERK1 or $1 \mu \mathrm{g} / \mathrm{sample}$ of AP-1 for JNK1) for $15 \mathrm{~min}$ at $30^{\circ} \mathrm{C}$. The kinase reaction was stopped by the addition of sample buffer. Samples were heated to $80^{\circ} \mathrm{C}$ for $5 \mathrm{~min}$ and loaded onto polyacrylamide gels. Quantitation of results was performed on a Molecular Dynamics PhosphorImager (Sunnyvale, CA).

For the MAPKAP2 assay, Cos7 cells were grown to confluency in a 60 $\mathrm{mm}$ dish. Cells were preincubated in serum-free medium containing either $0.0125 \%$ DMSO or $500 \mathrm{nM}$ CEP-1347 for $1 \mathrm{hr}$, followed by treatment with $500 \mathrm{~mm}$ sorbitol for $1 \mathrm{hr}$. Then cells were rinsed with ice-cold PBS and lysed in Triton buffer; lysate was normalized to protein concentration. Lysate was immunoprecipitated with the MAPKAP2 antibody and assayed for kinase activity with $0.125 \mathrm{mM}$ MAPKAP2 peptide substrate, as described by the provider. The kinase reaction was stopped with $75 \mathrm{~mm}$ phosphoric acid, loaded onto phosphocellulose filters (Pierce, Rockford, IL), and washed with $75 \mathrm{~mm}$ phosphoric acid, followed by elution with $1 \mathrm{~N} \mathrm{NaOH}$. Radioactivity from the eluate was counted in a Beckman LS3801 (Fullerton, CA).

Stress-induced JNK1 activity in Cos 7 cells. Cos 7 cells were grown to confluency in $60 \mathrm{~mm}$ plates. The cells were preincubated with $0.01 \%$ DMSO or $500 \mathrm{~nm}$ CEP-1347 for $1 \mathrm{hr}$, followed by the following stresses: $500 \mathrm{~mm}$ sorbitol for $1 \mathrm{hr}$; exposure to ultraviolet irradiation from the UV2400 Stratolinker (Stratagene, La Jolla, CA) for $5 \mathrm{~min}$, followed by 1 $\mathrm{hr}$ incubation at $37^{\circ} \mathrm{C}$; and $50 \mu \mathrm{g} / \mathrm{ml}$ tunicamycin for $5 \mathrm{hr}$. The cells were rinsed with cold PBS, lysed with Triton buffer, immunoprecipitated with the JNK1 antibody, and assayed for kinase activity as described above.

Overexpression of mitogen-activated kinase kinase kinase 1 (MEKK1) and JNK1 in Cos 7 cells. Cos 7 cells were plated to $80 \%$ confluency and transfected with $2 \mu \mathrm{g}$ each of cDNA constructs, using Lipofectamine as recommended by the provider (Life Technologies, Gaithersburg, MD). A truncated cDNA of mouse MEKK1 (corresponding to amino acids 817-1493 of full-length rat MEKK1) and full-length human JNK1, kindly provided by J. Silvio Gutkind (National Institutes of Health, Bethesda, MD), were subcloned into the pcDNA3 vector (Invitrogen, San Diego, CA). The JNK construct contained a hemagglutinin tag. After a $48 \mathrm{hr}$ transfection, the cells were treated with DMSO or $500 \mathrm{nM}$ CEP-1347 for $2 \mathrm{hr}$, followed by immunoprecipitation with the HA antibody. Immunoprecipitates were normalized for protein and assayed for kinase activity in the presence of $c$-jun substrate as described above. 


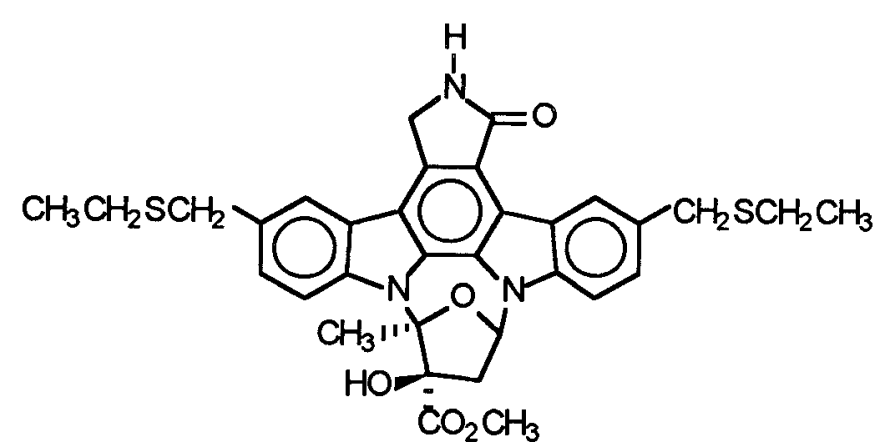

Figure 1. Structure of CEP-1347. CEP-1347 was synthesized by derivitization of K-252a, an indolocarbazole isolated from culture broths of Nocardiosis.

\section{RESULTS}

Low nanomolar concentrations of K-252a, a natural product indolocarbazole of the bacterium Nocardiosis species, induced ChAT activity in spinal cord cultures (Glicksman et al., 1993). The ChAT enzyme catalyzes the synthesis of the neurotransmitter, acetylcholine, and serves as a marker for motoneurons in spinal cord cultures (Phelps et al., 1988, 1990). This neurotrophic activity was optimized by examining novel K-252a analogs in embryonic rat spinal cord cultures and measuring ChAT activity. As reported elsewhere, an ethylthiomethyl analog of K-252a, CEP-1347 (for structure, see Fig. 1), exhibited greater efficacy $\left(250 \%\right.$ of control) and potency $\left(\mathrm{EC}_{50}=50 \mathrm{nM}\right)$ than $\mathrm{K}-252 \mathrm{a}$ in spinal cord ChAT assays (Kaneko et al., 1997).

The neurotrophic properties of CEP-1347 were not attributable to the inhibition of several known target kinases of K-252a. In contrast to the inhibition of several serine/threonine kinases by $\mathrm{K}-252 \mathrm{a}$ in the nanomolar range, the $\mathrm{IC}_{50}$ values of CEP-1347 for PKC, PKA, MLCK, and PI3K were all >10 $\mu \mathrm{M}$ (Table 1). K-252a inhibited trk tyrosine kinase activity with an $\mathrm{IC}_{50}$ of $2.5 \mathrm{~nm}$, whereas the $\mathrm{IC}_{50}$ of CEP-1347 was $>1 \mu \mathrm{M}$ (Table 1 ). These results demonstrated a broad separation of neurotrophic activity from inhibition of several known target kinases of K-252a.

To examine whether the increased ChAT activity in spinal cord cultures was attributable, at least in part, to motoneuron survival, we assessed the activity of CEP-1347 in cultures of enriched motoneurons. Cell viability in untreated cultures decreased by $35 \%$ after $48 \mathrm{hr}$ and by $65 \%$ after $72 \mathrm{hr}$. An inhibitor of p38, SB203580, did not rescue motoneurons from cell death (Fig. 2)
Table 1. Comparison of in vitro kinase inhibitory activity between $\mathrm{K}$ 252a and CEP-1347

\begin{tabular}{llc} 
& \multicolumn{1}{c}{$\mathrm{IC}_{50}(\mu \mathrm{M})$} & \\
\cline { 2 - 3 } Kinase & $\mathrm{K}-252 \mathrm{a}$ & $\mathrm{CEP}-1347$ \\
\hline PKC & 0.028 & 16.3 \\
PKA & 0.072 & $>10$ \\
MLCK & 0.19 & $>10$ \\
PI3K & 2.0 & $>10$ \\
TRK & 0.002 & $>1$ \\
\hline
\end{tabular}

(Cuenda et al., 1995). In contrast, viability in the presence of CEP-1347 did not differ substantially from cultures assayed at initial plating (Fig. 2).

The morphology of motoneuron cultures was assessed in the presence of CEP-1347. In contrast to control cultures that rapidly underwent neurite retraction and cellular fragmentation, those cells treated with CEP-1347 displayed a flattened cell body morphology with extensive neuritic processes for at least $5 \mathrm{~d}$ (Fig. $3 a, b)$. To determine whether cells in control cultures were dying by apoptosis, we examined chromatin condensation by staining the DNA with fluorescent Hoechst dye. By 48 hr a significant proportion of untreated motoneurons exhibited clear hallmarks of chromatin condensation, consistent with a previous report that cultures of enriched motoneurons in the absence of neurotrophic factors die in an apoptotic manner (Fig. 3c) (Comella et al., 1994; Milligan et al., 1994). In contrast, CEP-1347-treated cultures exhibited diff use nuclear staining, consistent with the survival activity detected by the calcein assay (Fig. $3 d$ ).

Changes in the activities of members in the MAPK family have been implicated in neuronal survival and apoptosis (Xia et al., 1995). We examined whether neuronal survival induced by CEP1347 was accompanied by changes in the activities of ERK1 and JNK1. The basal level of ERK1 activity did not change over time in untreated cultures, and $500 \mathrm{~nm}$ CEP-1347 had no significant effect on ERK1 activity (Fig. $4 A$ ). These data demonstrated that CEP-1347 promoted survival in the absence of a change in ERK1 activity. In contrast, JNK1 activity in untreated cultures increased approximately fourfold within $24 \mathrm{hr}$ after plating. As early as $15 \mathrm{~min}$ after the addition of $500 \mathrm{~nm}$ CEP-1347, JNK1 activity sharply decreased to $\sim 50 \%$ of control levels and continued to decrease for the next $24 \mathrm{hr}$ (Fig. 4B).
Figure 2. Time course of motoneuron death in the absence or presence of CEP-1347. Cells were plated at a density of $6 \times 10^{4}$ cells $/ \mathrm{cm}^{2}$ in chemically defined N2 medium. After 2 hr to allow for attachment, cells were incubated with $0.006 \%$ DMSO (control), $250 \mathrm{nM}$ CEP-1347, or 5-10 $\mu \mathrm{M} \mathrm{SB203580}$ and monitored for cell viability over $3 \mathrm{~d}$. Cell viability was measured by using the calcein AM assay as described in Materials and Methods. Experimental data represent the mean $\pm \mathrm{SD}, n=4$; DMSO control data represent the mean $\pm \mathrm{SD}, n=12$. Three independent experiments were performed; data presented are from one representative experiment. ${ }^{*} p<0.05$, by Dunnett's $t$ statistics, significantly different from control cultures.

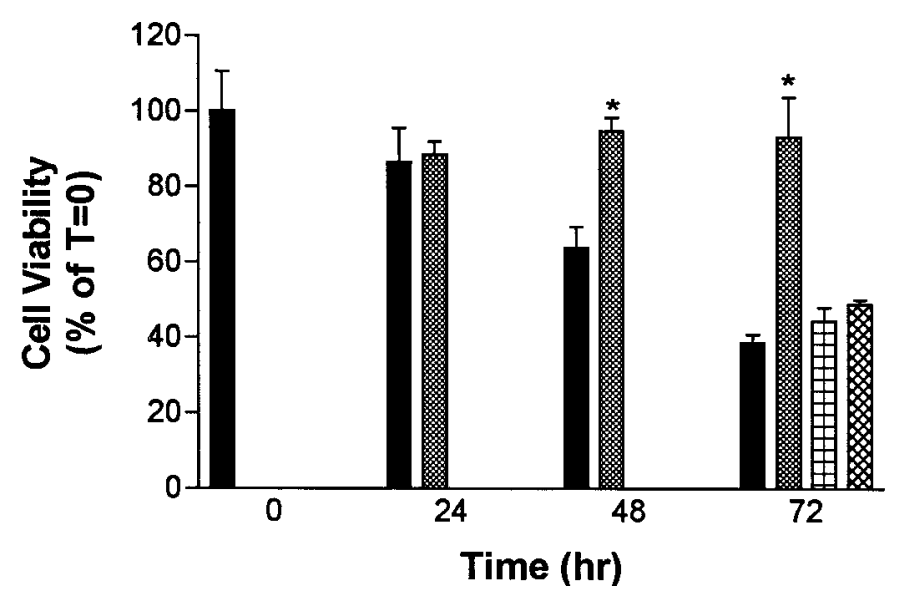

control

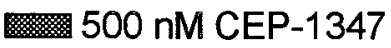

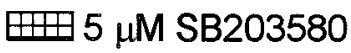
$10 \mu \mathrm{M}$ SB203580 


\section{CONTROL}
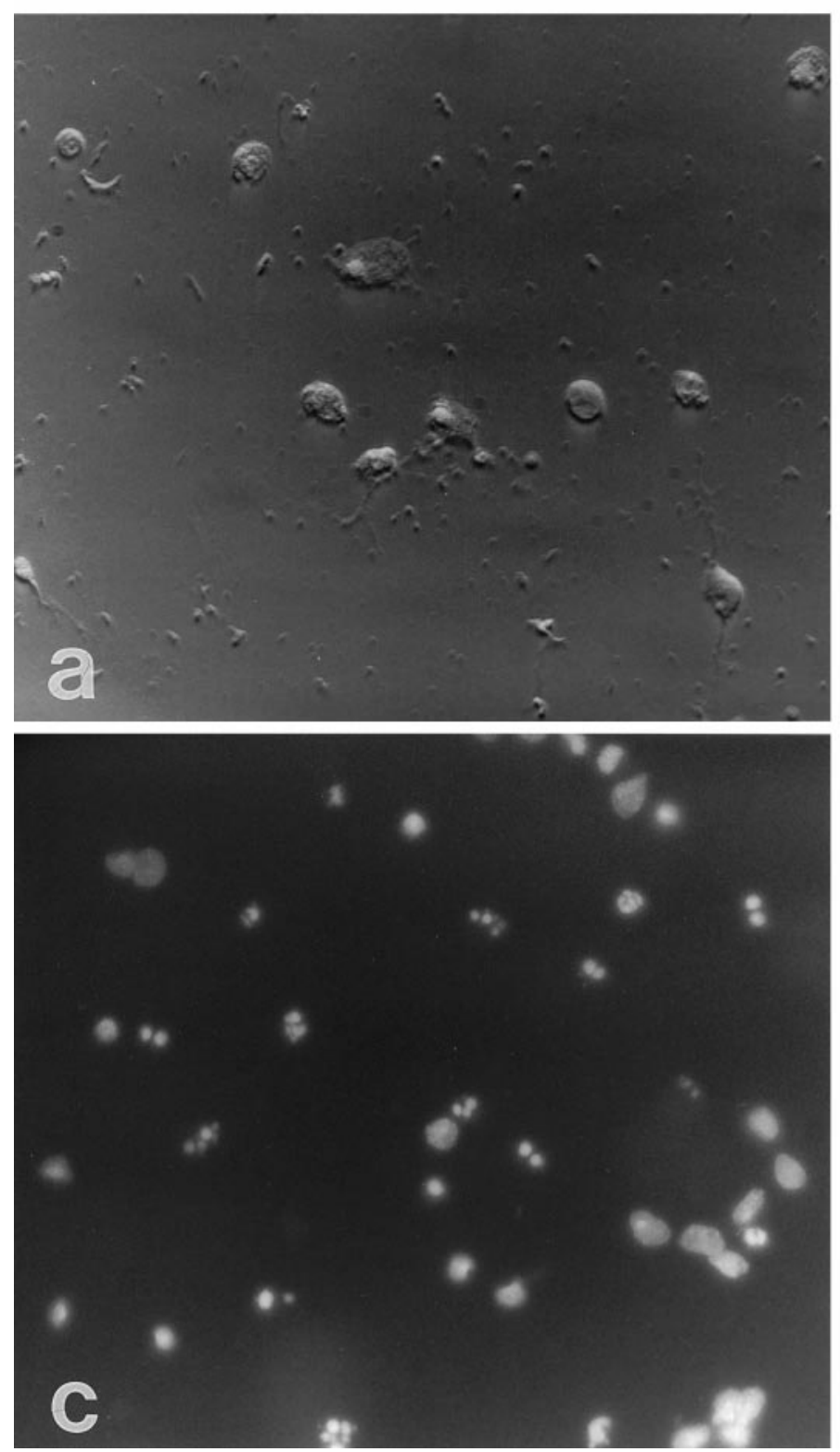

250 nM CEP1347
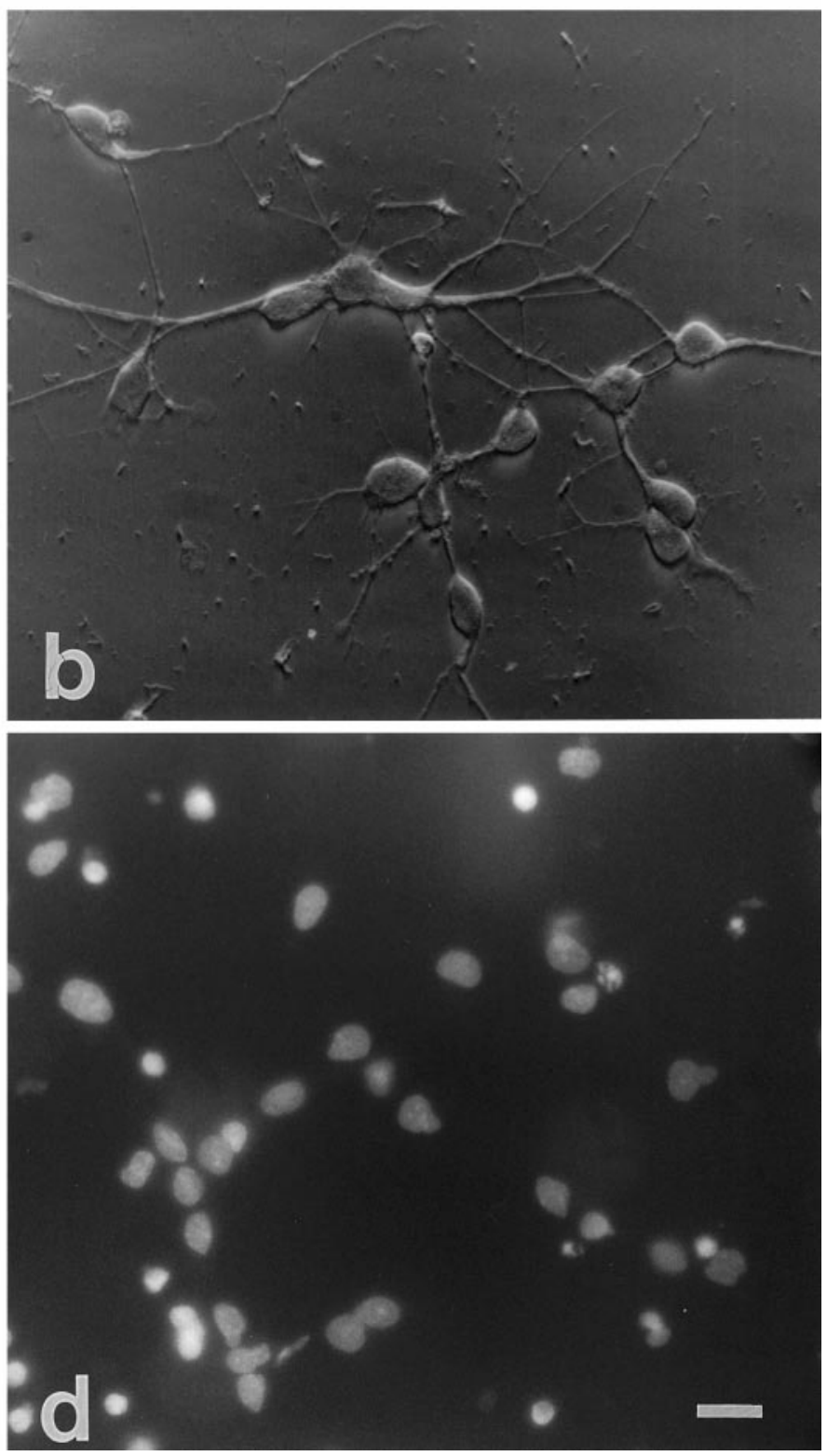

Figure 3. Apoptosis of enriched E14.5 motoneurons in the absence or presence of CEP-1347. Cells were plated at a density of $6 \times 10^{4}$ cells $/ \mathrm{cm}^{2}$ in chemically defined N2 medium. After 2 hr to allow for attachment, control cells were incubated with $0.006 \%$ DMSO control (a, $c)$ or 250 nM CEP-1347 $(b, d)$ for $5 \mathrm{~d}$, followed by fixation and photography with Hoffman modulating contrast optics $(a, b)$, or for $2 \mathrm{~d}$, followed by staining with Hoechst dye $(c, d)$ to detect condensed chromatin.

To resolve whether inhibition of JNK1 activity by CEP-1347 correlated with motoneuron survival, we compared the $\mathrm{IC}_{50}$ for JNK1 activity with the $\mathrm{EC}_{50}$ for survival by CEP-1347. Cultures enriched for motoneurons were grown in the presence of increasing concentrations of CEP-1347, and JNK1 activity and cell survival were determined. The $\mathrm{IC}_{50}$ for $\mathrm{JNK} 1$ activity measured at $22 \mathrm{hr}$ was $21 \pm 2 \mathrm{~nm}$, whereas the $\mathrm{EC}_{50}$ for cell survival measured at $5 \mathrm{~d}$ was $20 \pm 2 \mathrm{~nm}$ (Fig. 5). These results suggested that cell survival and inhibition of JNK1 activity by CEP-1347 were integrally linked processes.

To determine whether the observed decrease in JNK1 activation was secondary to effects on neuronal survival or was an intrinsic property of CEP-1347, we examined the effect of CEP-
1347 on JNK1 activation in Cos7 cells exposed to various external stresses. JNK1 activity increased after treatment with irradiation, sorbitol, and tunicamycin, consistent with previous studies (Derijard et al., 1994; Kyriakis et al., 1994; Rosette and Karin, 1996; Zanke et al., 1996) (Table 2a). CEP-1347 prevented the increase in JNK1 activity to a significant degree under all three stress conditions. Therefore, inhibition of JNK1 activation by CEP-1347 was not neuronal or stimuli-specific. In addition, inhibition of JNK1 activation was not a consequence of neuronal survival but appears to be an intrinsic property of CEP-1347.

Because p38 also has been implicated in neuronal apoptosis (Xia et al., 1995), it was of interest to determine whether CEP1347 inhibited the p38 signaling pathway. MAPKAP2 is a sub- 
A.

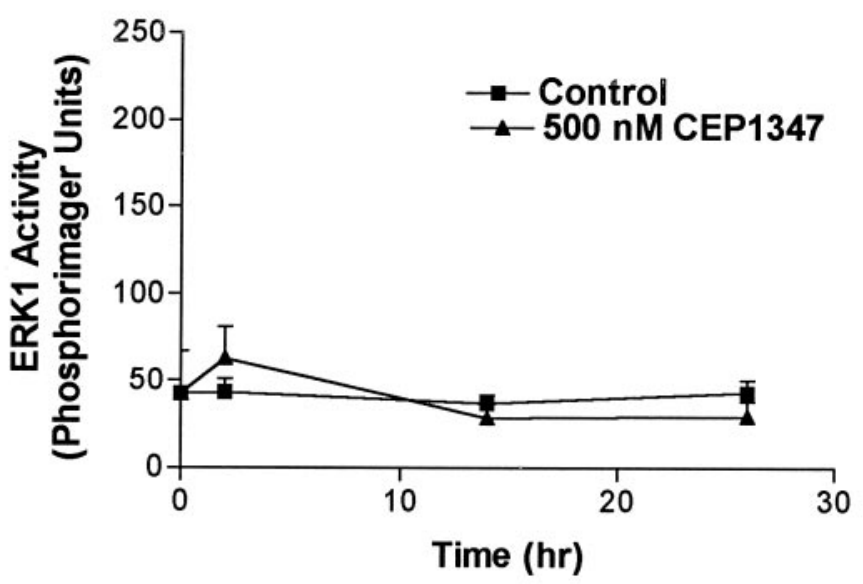

B.

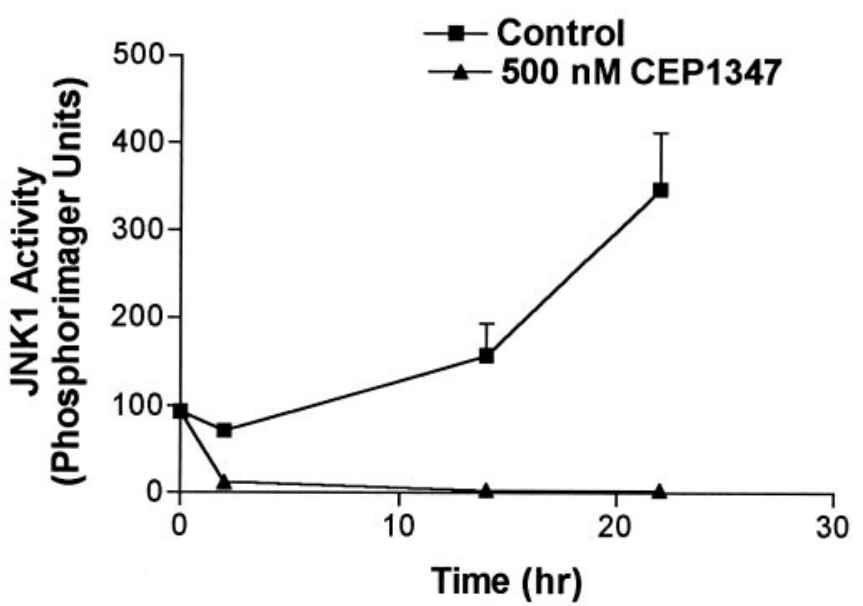

Figure 4. ERK1 and JNK1 activity in the absence or presence of CEP-1347. Cultures of enriched E14.5 motoneurons were treated with $0.01 \%$ DMSO control or $500 \mathrm{nM}$ CEP-1347 for various times, as indicated. Cells were lysed in $1 \%$ Triton buffer, and the lysate was immunoprecipitated with the ERK1 $(A)$ or JNK1 $(B)$ antibody. The immunoprecipitates were assayed for kinase activity by using myelin basic protein or c-Jun, respectively, as substrates. Experiments were performed at least two times, and results from representative experiments are shown. Points represent the average of duplicate samples; error bars indicate the SEM.

strate of p38 and reflects p38 activation (Rouse et al., 1994). Attempts to measure p38 activity in motoneurons by assaying the activity of MAPKAP2 were unsuccessful, probably because of a lack of detection sensitivity in the low-density motoneuron cultures. We therefore tested the effect of CEP-1347 on MAPKAP2 activity in osmotically stressed Cos7 cells, a treatment that has been shown previously to activate p38 (Raingeaud et al., 1995). CEP-1347 had no effect on MAPKAP2 activity, whereas a p38 inhibitor, SB203580, completely blocked the stress-induced p38 activity (Table 2b) (Cuenda et al., 1995). These data suggested that CEP-1347 did not inhibit p38 directly or inhibit the upstream regulators of the osmotic shock-induced MAPKAP2 activity.

To determine whether JNK1 was a direct molecular target of CEP-1347 in Cos7 cells, we overexpressed cDNA constructs of
HA-JNK1 alone or with an upstream activator of JNK1, MEKK1 (Lange-Carter et al., 1993; Minden et al., 1994), and examined JNK1 activity in the absence or presence of CEP-1347. After a $48 \mathrm{hr}$ transfection, the JNK1 activity in Cos7 cells cotransfected with varying amounts of MEKK and HA-JNK1 constructs was $\sim$ threefold to 50 -fold above the JNK1 activity in cells transfected with HA-JNK1 alone (Fig. 6). CEP-1347 did not prevent JNK1 activity under any of the conditions tested. These results indicated that JNK1 was not the direct molecular target of CEP-1347 and that the molecular target of CEP-1347 was either upstream of MEKK1 or independent of an MEKK1-activated JNK1 pathway.

\section{DISCUSSION}

We have shown that CEP-1347 rescues motoneurons from apoptotic death in vitro (see Fig. 2) and that survival correlates with the inhibition of JNK1 activation (see Figs. 4, 5). An endogenous substrate of JNK1 is the nuclear transcription factor $c$-jun (Hibi et al., 1993; Derijard et al., 1994; Kyriakis et al., 1994), and CEP1347 suppressed $c$-jun mRNA in motoneurons at $24 \mathrm{hr}$ after treatment (M. Glicksman, unpublished data). This is consistent with reports demonstrating that a dominant negative mutant of $c$-jun or a $c$-jun neutralizing antibody blocks apoptosis induced by neurotrophin withdrawal in SCG neurons and in PC12 cells (Estus et al., 1994; Ham et al., 1995; Xia et al., 1995). Furthermore, a dominant negative mutant of MEKK1, which is one upstream regulator of JNK activation, blocked apoptosis in NGFwithdrawn neuronally differentiated PC12 cells (Xia et al., 1995). These data provide convincing evidence to implicate the JNK signaling cascade in neuronal models of cell death. However, the sufficiency of JNK and $c$-jun activation to promote cell death is questionable. In SCG neurons undergoing prolonged NGF deprivation, suppression of elevated JNK activity by the readdition of NGF is insufficient to rescue all of the cells (Virdee et al., 1997). Furthermore, $c$-jun is elevated in cholinergic neurons after fornix-fimbria transection, and these cells do not die (Butterworth and Dragunow, 1996). These reports suggest that, in addition to $\mathrm{JNK} / c$-jun activation, other signaling events may be involved in committing neurons to a death pathway.

A role for $\mathrm{JNK}$ in the induction of apoptosis also has been examined in non-neuronal systems. Inhibiting JNK or kinases upstream of JNK protects different cell types from death induced by a variety of stimuli such as camptothecin, thermal shock, cis-platinum, and ceramide (Verheij et al., 1996; Zanke et al., 1996; Ichijo et al., 1997; Seimiya et al., 1997). However, inactivation of the JNK signaling cascade does not protect against all types of stress-induced death. For example, high doses of arabinofuranosylcytosine lead to apoptosis in monocytic leukemia U937 cells, and this death is not blocked with a dominant negative mutant of c-Jun (Grant et al., 1996). Also, developmental PCD occurs in $c$-jun null embryos, suggesting that $c$-jun is not essential for apoptosis to occur in a variety of tissues (Roffler-Tarlov et al., 1996); in one study CD95- and CD3-mediated apoptosis was exacerbated in MEK4 null immature thymocytes (Nishina et al., 1997). Furthermore, the addition of tumor necrosis factor- $\alpha$ leads to apoptosis in many cell types and activates the JNK pathway; however, the role of JNK activation in these apoptotic models is controversial (Gardner and Johnson, 1996; Liu et al., 1996; Verheij et al., 1996; Natoli et al., 1997). Certainly, multiple pathways leading to cell death exist and may have different dependencies on the MAPKs for functional outcome, subject to the death stimulus and cellular environment. 


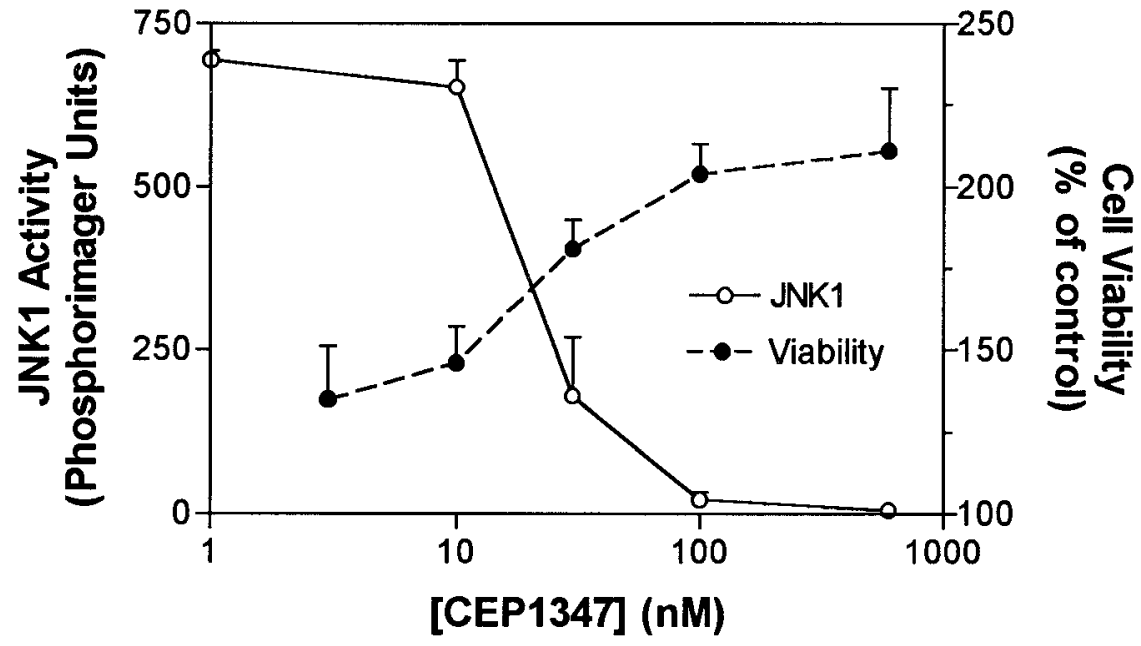

Figure 5. Dose-response of inhibition of JNK1 activity and cell survival by CEP-1347. Cultures of enriched E14.5 motoneurons were plated and allowed to adhere $2.5 \mathrm{hr}$ before the addition of the indicated concentrations of CEP-1347. For JNK1 activity, cells were collected $22 \mathrm{hr}$ after the addition of compound and assayed for kinase activity as described in Figure 4; cell viability was determined by calcein AM assay after $5 \mathrm{~d}$ in culture. The percentage of cell viability is relative to untreated controls, which is equivalent to $100 \%$. Points represent the average of duplicate samples; the error bars indicate the SEM.
Dominant negative forms of various components of the JNK/ p38 signaling pathway interfere with death, whereas constitutively active forms of components in the ERK signaling pathway promote survival after NGF withdrawal from neuronally differentiated PC12 cells (Xia et al., 1995). These results suggest that an opposing balance between the ERK and stress-activated kinases may be crucial for determining whether a cell survives or dies. However, NGF promotes survival in SCG in the presence of the MEK1 inhibitor, PD98059, which blocks ERK activation (Creedon et al., 1996; Virdee and Tolkovsky, 1996). Furthermore, sustained activation of ERK is insufficient to promote survival in hippocampal pyramidal neurons (Marsh and Palfrey, 1996). Because CEP-1347 promotes survival in the absence of any effect on ERK1 activity, results reported here support evidence that ERK activation is not necessary or essential for neuronal survival. Although we could not measure MAPKAP2 activity in the motoneuron model, CEP-1347 does not inhibit MAPKAP2 activity in sorbitol-treated Cos7 cells (Table 2). Furthermore, the p38 inhibitor, SB203580, inhibits MAPKAP2 activity in Cos7 cells (Table 2; Cuenda et al., 1995) but does not promote motoneuron survival (see Fig. 2). These data suggest that inhibition of p38 is not sufficient for motoneuron survival. Taken together, we con-

\section{Table 2. Activity in Cos7 cells}

JNK1 activity in stressed-induced Cos7 cells

\begin{tabular}{lll} 
Treatment & Control & CEP-1347 \\
\hline Untreated & 1.0 & 1.0 \\
Irradiation & 5.3 & 2.4 \\
Sorbitol & 7.8 & 2.4 \\
Tunicamycin & 1.6 & 0.9 \\
\hline
\end{tabular}

MAPKAP2 activity in osmotic shocked Cos7 cells

\begin{tabular}{llll} 
Treatment & Control & CEP-1347 & SB203580 \\
\hline Untreated & 1.0 & 1.4 & 0.6 \\
Sorbitol & 8.1 & 7.6 & 1.0 \\
\hline
\end{tabular}

Cells were grown to confluency and pretreated with DMSO, 500 nм CEP-1347, or $10 \mu \mathrm{M}$ SB203580 for $1 \mathrm{hr}$ before treatment with UV irradiation (5 min in Stratolinker, followed by $1 \mathrm{hr}$ incubation at $\left.37^{\circ} \mathrm{C}\right)$, sorbitol $(500 \mathrm{~mm}$ sorbitol for $1 \mathrm{hr}$ ), or tunicamycin $(50 \mu \mathrm{g} / \mathrm{ml}$ for $5 \mathrm{hr})$. Lysates were collected, normalized for protein, and immunoprecipitated with the JNK1 or MAPKAP2 antibody, as described in Materials and Methods. Experiments were performed at least two times, and results from a representative experiment are shown. Results are expressed as the fold increase relative to untreated control. clude that the activity of the MAPK members is not tightly coupled in an opposing relationship during motoneuronal survival/death processes.

The enhancement of motoneuronal survival by CEP-1347 in vitro is comparable to that elicited by optimal concentrations of protein growth factors (Arakawa et al., 1990; Henderson et al., 1993, 1994; Hughes et al., 1993). CEP-1347 does not exhibit selectivity for motoneurons but is also neurotrophic for neurons dissociated from other regions of the vertebrate embryo, for example, spinal cord and basal forebrain (Kaneko et al., 1997), dorsal root ganglia, striatum, basal forebrain, and entorhinal cortex (M. Glicksman, unpublished data).

Growth factors, such as BDNF and IGF-1, rescue motoneurons from trophic deprivation-induced cell death. In our hands the effect of BDNF on motoneuron survival was highly dependent on cell density. Under extremely stringent conditions $\left(200\right.$ cells $\left./ \mathrm{cm}^{2}\right)$ BDNF, as well as CEP-1347, rescued motoneurons. This lowdensity plating prohibited biochemical analysis of signaling pathways. However, at higher plating density, as presented in this manuscript, BDNF activated ERK1 but did not promote survival nor inhibit the rise in JNK1 activity (data not shown). Thus, BDNF-induced ERK1 activation was not sufficient for motoneuron survival in these cultures. The mechanism by which growth factors promote survival of neurons is unclear and perhaps may depend on the activation of other proteins such as phosphatidylinositol-3 kinase and Akt, which ultimately may lead to a decrease in JNK activity (Yao and Cooper, 1995; Dudek et al., 1997).

Inhibition of JNK1 activation appears to be an intrinsic property of CEP-1347, because the activation of JNK1 by multiple stress stimuli also was blocked by CEP-1347 in Cos7 cells (Table 2). Because different stimuli can activate JNK via distinct pathways, these data suggest that CEP-1347 is acting at a site at or proximal to JNK itself. Directly upstream of JNK is MEK4, which can be phosphorylated by a number of kinases, one of which is MEKK1 (Lange-Carter et al., 1993; Minden et al., 1994; Derijard et al., 1995; Lin et al., 1995). Transfection data reported here suggest that JNK1 is not the direct target of CEP-1347 and that the molecular target is either upstream or independent of MEKK1. Kinases of the germinal center and multiple lineage kinase families activate JNK independently of MEKK1 and are also potential targets for CEP-1347 action (for review, see Fanger et al., 1997). As has been shown in Table 1, CEP-1347 does not 


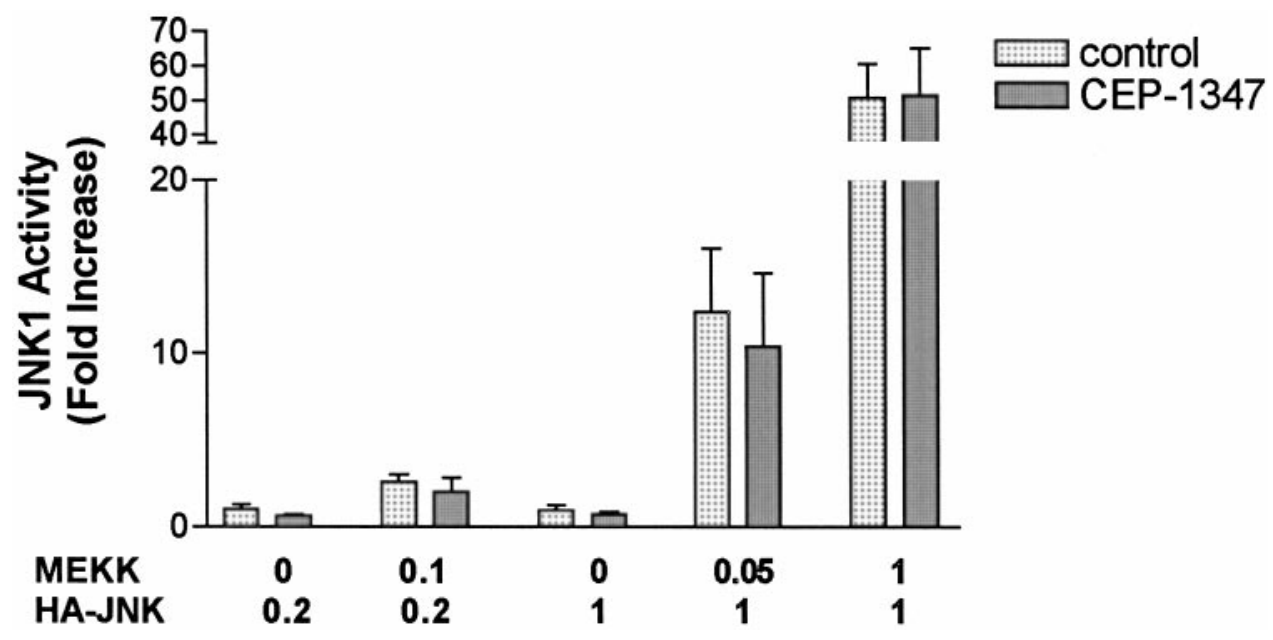

Figure 6. JNK1 activity in Cos7 cells overexpressing HA-JNK1 alone or with MEKK1. Cos7 cells were grown to $80 \%$ confluency and transfected with HA-tagged JNK1 alone or with MEKK1 at various amounts of cDNA, as indicated. After a $48 \mathrm{hr}$ period the cells were incubated with $0.01 \%$ DMSO or $500 \mathrm{nM}$ CEP-1347 for $2 \mathrm{hr}$, followed by lysis in 1\% Triton buffer. Lysate was normalized to protein and immunoprecipitated with HA antibody. The immunoprecipitates were assayed for kinase activity with the $c$-jun substrate. Experiments were performed at least two times, and results from representative experiments are shown. Activity is expressed by fold increase relative to untreated HA-JNK-transfected cells. Columns represent the average of duplicate samples; the error bars indicate the SEM.

display the broad kinase inhibitory activities of K-252a. Although CEP-1347 appears to be more selective than K-252a, it also may have multiple cellular targets.

The recent discovery of stress-activated signaling pathways in dying neurons broadens the concept of neurotrophism, which classically has been defined by activation of the ras signaling cascade by NGF, resulting in the attenuation of death (Borasio et al., 1989; Nobes and Tolkovsky, 1995; Weng et al., 1996). We have demonstrated here that a nonpolypeptide organic molecule can attenuate neuronal death without the activation of a MAPK pathway. Importantly, CEP-1347-mediated motoneuron survival correlates with the inhibition of the JNK signaling cascade. These observations suggest that intervention in the JNK signaling cascade may offer opportunities for the development of therapeutic agents for neurodegenerative disease.

\section{REFERENCES}

Angeles TS, Steffler C, Bartlett BA, Hudkins RL, Stephens RM, Kaplan DR, Dionne CA (1996) Enzyme-linked immunosorbent assay for trkA tyrosine kinase activity. Anal Biochem 236:49-55.

Arakawa Y, Sendtner M, Thoenen H (1990) Survival effect of ciliary neurotrophic factor (CNTF) on chick embryonic motoneurons in culture: comparison with other neurotrophic factors and cytokines. J Neurosci 10:3507-3515.

Borasio GD (1990) Differential effects of the protein kinase inhibitor $\mathrm{K}-252 \mathrm{a}$ on the in vitro survival of chick embryonic neurons. Neurosci Lett 108:207-212.

Borasio GD, John J, Wittinghofer A, Barde Y-A, Sendtner M, Heumann R (1989) p21 ras protein promotes survival and fiber outgrowth of cultured embryonic neurons. Neuron 2:1087-1096.

Bottenstein J, Sato G (1979) Growth of a rat neuroblastoma cell line in serum-free supplemented medium. Proc Natl Acad Sci USA 76:514-517.

Bozyczko-Coyne D, McKenna BW, Connors TJ, Neff NT (1993) A rapid fluorimetric assay to measure neuronal survival in vitro. J Neurosci Methods 50:205-216.

Butterworth NJ, Dragunow M (1996) Medial septal cholinergic neurons express c-Jun but do not undergo DNA fragmentation after fornixfimbria transections. Mol Brain Res 43:1-12.

Cheng B, Barger SW, Mattson MP (1994) Staurosporine, K-252a, and K-252b stabilize calcium homeostasis and promote survival of CNS neurons in the absence of glucose. J Neurochem 62:1319-1329.

Comella JX, Sanz-Rodriguez C, Aldea M, Esquerda JE (1994) Skeletal muscle-derived trophic factors prevent motoneurons from entering an active cell death program in vitro. J Neurosci 14:2674-2686.

Creedon DJ, Johnson Jr EM, Lawrence Jr JC (1996) Mitogen-activated protein kinase-independent pathways mediate the effects of nerve growth factor and cAMP on neuronal survival. J Biol Chem 271:20713-20718.

Cuenda A, Rouse J, Doza YN, Meier R, Cohen P, Gallagher TF, Young PR, Lee JC (1995) SB203580 is a specific inhibitor of a MAP kinase homologue which is stimulated by cellular stresses and interleukin-1. FEBS Lett 364:229-233.

Denhardt DT (1996) Signal-transducing protein phosphorylation cascades mediated by Ras/Rho proteins in the mammalian cell: the potential for multiplex signaling. Biochem J 318:729-747.

Dérijard B, Hibi M, Wu I-H, Barrett T, Su B, Deng T, Karin M, Davis RJ (1994) JNK1: a protein kinase stimulated by UV light and Ha-Ras that binds and phosphorylates the c-Jun activation domain. Cell 76:1025-1037.

Dérijard B, Raingeaud J, Barrett T, Wu I-H, Han J, Ulevitch RJ, Davis RJ (1995) Independent human MAP kinase signal transduction pathways defined by MEK and MKK isoforms. Science 267:682-685.

Dudek H, Datta SD, Franke TF, Bimbaum MJ, Yao R, Cooper GM, Segal RA, Kaplan DK, Greenberg ME (1997) Regulation of neuronal survival by the serine-threonine kinase Akt. Science 275:661-665.

Estus S, Zaks WJ, Freeman RS, Gruda M, Bravo R, Johnson Jr EM (1994) Altered gene expression in neurons during programmed cell death: identification of $c$-jun as necessary for neuronal apoptosis. J Cell Biol 127:1717-1727.

Fanger GR, Gerwins P, Widmann C, Jarpe MB, Johnson GL (1997) MEKKs, GCKs, MLKs, PAKs, TAKs, and TPLs: upstream regulators of the c-Jun amino-terminal kinases? Curr Opin Genet Dev 7:67-74.

Gardner AM, Johnson GL (1996) Fibroblast growth factor-2 suppression of tumor necrosis factor $\alpha$-mediated apoptosis requires RAS and the activation of mitogen-activated protein kinase. J Biol Chem 271:14560-14566.

Glicksman MA, Prantner JE, Meyer SL, Forbes ME, Dasgupta M, Lewis ME, Neff NT (1993) K-252a and staurosporine promote choline acetyltransferase activity in rat spinal cord cultures. J Neurochem 61:210-221.

Glicksman MA, Forbes ME, Prantner JE, Neff NT (1995) K-252a promotes survival and choline acetyltransferase activity in striatal and basal forebrain neuronal cultures. J Neurochem 64:1502-1512.

Grant S, Freemerman AJ, Birrer MJ, Martin HA, Turner AJ, Szabo E, Chelliah J, Jarvis WD (1996) Effect of 1- $\beta$-D-arabinofuranosylcytosine on apoptosis and differentiation in human monocytic leukemia cells (U937) expressing a c-Jun dominant-negative mutant protein (TAM67). Cell Growth Differ 7:603-613. 
Ham J, Babij C, Whitfield J, Pfarr CM, Lallemand D, Yaniv M, Rubin LL (1995) A c-Jun dominant negative mutant protects sympathetic neurons against programmed cell death. Neuron 14:927-939.

Heidenreich KA, Kummer JL (1996) Inhibition of p38 mitogenactivated protein kinase by insulin in cultured fetal neurons. J Biol Chem 271:9891-9894.

Henderson CE, Camu W, Mettling C, Gouin A, Poulsen K, Karihaloo M, Rullamas J, Evans T, McMahon SB, Armanini MP, Berkemeier L, Phillips HS, Rosenthal A (1993) Neurotrophins promote motor neuron survival and are present in embryonic limb bud. Nature 363:266-270.

Henderson CE, Phillips HS, Pollock RA, Davies AM, Lemeulle C, Armanini M, Simpson LC, Moffet B, Vandlen RA, Koliatsos VE, Rosenthal A (1994) GDNF: a potent survival factor for motoneurons present in peripheral nerve and muscle. Science 266:1062-1064.

Hibi M, Lin A, Smeal T, Minden A, Karin M (1993) Identification of an oncoprotein- and UV-responsive protein kinase that binds and potentiates the c-jun activation domain. Genes Dev 7:2135-2148.

Hughes RA, Sendtner M, Thoenen H (1993) Members of several gene families influence survival of rat motoneurons in vitro and in vivo. J Neurosci Res 36:663-671.

Ichijo H, Nishida E, Irie K, Dijke P, Saitoh M, Moriguchi T, Takagi M, Matsumoto K, Miyazono K, Gotoh Y (1997) Induction of apoptosis by ASK1, a mammalian MAPKKK that activates SAPK/JNK and p38 signaling pathways. Science 275:90-94.

Kaneko M, Saito Y, Saito H, Matsumoto T, Matsuda Y, Vaught JL, Dionne CA, Angeles TS, Glicksman MA, Neff NT, Rotella DP, Kauer JC, Mallamo JP, Hudkins RL, Murakata C (1997) Neurotrophic 3,9alkylthiomethyl- and -alkoxymethyl-K-252a derivatives. J Med Chem 40:1863-1869.

Kase H, Iwahashi K, Nakanishi S, Matsuda Y, Yamada K, Takahashi M, Murakata C, Sato A, Kaneko M (1987) K-252 compounds, novel and potent inhibitors of protein kinase $\mathrm{C}$ and cyclic nucleotide-dependent protein kinases. Biochem Biophys Res Commun 142:436-440.

Kyriakis JM, Banerjee P, Nikolakaki E, Dal T, Rubie EA, Ahmad MF, Avruch J, Woodgett JR (1994) The stress-activated protein kinase subfamily of c-Jun kinases. Nature 369:156-160.

Lange-Carter CA, Pleiman CM, Gardner AM, Blumer KJ, Johnson GL (1993) A divergence in the MAP kinase regulatory network defined by MEK kinase and raf. Science 260:315-319.

Lin A, Minden A, Martinetto H, Claret F-X, Lange-Carter C, Mercurio F, Johnson GL, Karin M (1995) Identification of a dual specificity kinase that activates the Jun kinases and p38-Mpk2. Science 268:286-290.

Liu A-G, Hsu H, Goeddel DV, Karin M (1996) Dissection of TNF receptor 1 effector functions: JNK activation is not linked to apoptosis while NF- $\kappa$ B activation prevents cell death. Cell 87:565-576.

Maroney AC, Lipfert L, Forbes ME, Glicksman MA, Neff NT, Siman R, Dionne CA (1995) K-252a induces tyrosine phosphorylation of the focal adhesion kinase and neurite outgrowth in human neuroblastoma SH-SY5Y cells. J Neurochem 64:540-549.

Marsh HN, Palfrey HC (1996) Neurotrophin-3 and brain-derived neurotrophic factor activate multiple signal transduction events but are not survival factors for hippocampal pyramidal neurons. J Neurochem 67:952-963.

Milligan CE, Oppenheim RW, Schwartz LM (1994) Motoneurons deprived of trophic support in vitro require new gene expression to undergo programmed cell death. J Neurobiol 25:1005-1016.

Minden A, Lin A, McMahon M, Lange-Carter C, Dérijard B, Davis RJ, Johnson GL, Karin M (1994) Differential activation of ERK and JNK mitogen-activated protein kinases by Raf-1 and MEKK. Science 266:1719-1724.

Nakanishi S, Kase H, Matsuda Y (1991) Assay of myosin light chain kinase activity by high-performance liquid chromatography using a synthetic peptide as substrate. Anal Biochem 195:313-318.

Natoli G, Costanza A, Ianni A, Templeton DJ, Woodgett JR, Balsano C,
Levrero M (1997) Activation of SAPK/JNK by TNF receptor 1 through a noncytotoxic TRAF2-dependent pathway. Science 275:200-203.

Nishina H, Fischer KD, Radvanyl L, Shahlnian A, Hakem R, Rubie EA, Bernstein A, Mak TW, Woodgett JR, Penninger JM (1997) Stresssignaling kinase Sek1 protects thymocytes from apoptosis mediated by CD95 to CD3. Nature 385:350-353.

Nobes CD, Tolkovsky AM (1995) Neutralizing anti-p21 ras Fabs suppress rat sympathetic neuron survival induced by NGF, LIF, CNTF, and cAMP. Eur J Neurosci 7:344-350.

Oppenheim RW (1991) Cell death during development of the nervous system. Annu Rev Neurosci 14:453-501.

Phelps PE, Barber RP, Vaughn JE (1988) Generation patterns of four groups of cholinergic neurons in rat cervical spinal cord: a combined tritiated thymidine autoradiographic and choline acetyltransferase immunocytochemical study. J Comp Neurol 273:459-472.

Phelps PE, Barber RP, Brennan LA, Maines VM, Salveterra PM, Vaughn JE (1990) Embryonic development of four different subsets of cholinergic neurons in rat cervical spinal cord. J Comp Neurol 291:9-26.

Raingeaud J, Gupta S, Rogers JS, Dickens M, Han J, Ulevitch RJ, Davis RJ (1995) Pro-inflammatory cytokines and environmental stress cause p38 mitogen-activated protein kinase activation by dual phosphorylation on tyrosine and threonine. J Biol Chem 270:7420-7426.

Roffler-Tarlov S, Gibson Brown JJ, Tarlov E, Stolarov J, Chapman DL, Alexiou M, Papaioannou VE (1996) Programmed cell death in the absence of c-Fos and c-Jun. Development 122:1-9.

Rosette C, Karin M (1996) Ultraviolet light and osmotic stress: activation of the JNK cascade through multiple growth factor and cytokine receptors. Science 274:1194-1197.

Rouse J, Cohen P, Trigon S, Morange M, Alonso-Llamazares A, Zamanillo D, Hunt T, Nebreda AR (1994) A novel kinase cascade triggered by stress and heat shock that stimulates MAPKAP kinase-2 and phosphorylation of the small heat shock proteins. Cell 78:1027-1037.

Seimiya H, Mashima T, Toho M, Tsuruo T (1997) c-Jun $\mathrm{NH}_{2}$-terminal kinase-mediated activation of interleukin- $1 \beta$ converting enzyme/CED3 -like protease during anticancer drug-induced apoptosis. J Biol Chem 272:4631-4636.

Verheij M, Bose R, Lin XH, Yao B, Jarvis WD, Grant S, Birrer MJ, Szabo E, Zon LI, Kyriakis JM, Halmovitz-Friedman A, Fuks A, Kolesnick RN (1996) Requirement for ceramide-initiated SAPK/JNK signaling in stress-induced apoptosis. Nature 380:75-79.

Virdee K, Tolkovsky AM (1996) Inhibition of p42 and p44 mitogenactivated protein kinase activity by PD98059 does not suppress nerve growth factor-induced survival of sympathetic neurones. J Neurochem 67:1801-1805.

Virdee K, Bannister AJ, Hunt SP, Tolkovsky AM (1997) Comparison between the timing of JNK activation, c-Jun phosphorylation, and onset of death commitment in sympathetic neurons. J Neurochem 69:550-561.

Weng G, Markus MA, Markus A, Winkler A, Borasio GD (1996) p21 ras supports the survival of chick embryonic motor neurones. NeuroReport 7:1077-1081.

Xia Z, Dickens M, Raingeaud J, Davis RJ, Greenberg ME (1995) Opposing effects of ERK and JNK-p38 MAP kinases on apoptosis. Science 270:1326-1331.

Yano H, Nakanishi S, Kimura K, Hanai N, Saitoh Y, Fuku Y, Nonomura Y, Matsuda Y (1993) Inhibition of histamine secretion by wortmannin through the blockade of phosphatidylinositol-3 kinase in RBL-2H3 cells. J Biol Chem 268:25846-25856.

Yao RI, Cooper GM (1995) Requirement for phosphatidylinositol-3 kinase in the prevention of apoptosis by nerve growth factor. Science 267:5206-5208.

Zanke BW, Boudreau K, Rubie E, Winnett E, Tibbles LA, Zon L, Kyriakis J, Liu F-F, Woodgett JR (1996) The stress-activated protein kinase pathway mediates cell death following injury induced by cisplatinum, UV irradiation, or heat. Curr Biol 6:606-613. 